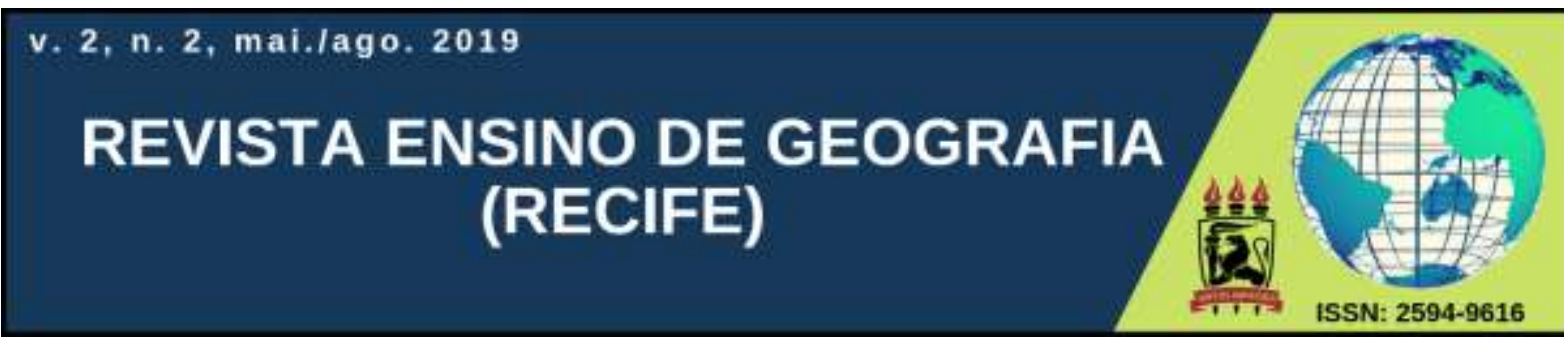

\title{
FUNDAMENTOS TEÓRICOS PARA O DESENVOLVIMENTO DO RACIOCÍNIO GEOGRÁFICO NA EDUCAÇÃO BÁSICA
}

\author{
Daniel Rodrigues Silva Luz Neto \\ Mestre em Geografia (Universidade de Brasília - UnB), Professor da Educação Básica \\ jonaspenhamarques@gmail.com \\ ORCID iD: http://orcid.org/0000-0002-6326-4906
}

Artigo recebido em 11/10/2019 e aceito em 17/07/2019

\begin{abstract}
RESUMO: Raciocínio geográfico é um processo cognitivo que pode ser desenvolvido pelo professor de Geografia tanto no ensino superior quanto no básico. Na educação básica, tem como função desenvolver o aluno para interpretar e atuar nas práticas espaciais. Não obstante, essa expressão ainda não é consensual entre os geógrafos e se encontra em estado probatório, pois começou a aparecer nas discussões da Geografia Escolar principalmente a partir da década 1990. Por isso, o objetivo deste trabalho é discutir indicações teóricas para o desenvolvimento de tal raciocínio na educação básica. Para isso foi utilizada a pesquisa bibliográfica na qual se permitiu chegar aos seguintes resultados; os conceitos estruturantes (espaço, paisagem, território) e os princípios lógicos (escala, localização, delimitação, conexão) são as bases teóricas para o desenvolvimento do raciocínio geográfico na educação básica. Portanto, o raciocínio geográfico é um processo cognitivo que possibilita a mobilização de habilidades para interpretar e atuar em práticas espaciais de maneira crítico-reflexiva. O seu desenvolvimento no ensino de Geografia na educação básica requer os fundamentos científicos da Geografia enquanto ciência.
\end{abstract}

Palavras-chave: Ensino; Raciocínio; Geográfico.

\section{THEORETICAL FOUNDATIONS FOR THE DEVELOPMENT OF GEOGRAPHICAL REACTION IN BASIC EDUCATION}

\begin{abstract}
Geographical reasoning is a cognitive process that can be developed by the Geography teacher in both higher and lower education. In basic education, the purpose is to develop the student to interpret and act in space practices. Nevertheless, this expression is not yet consensual among geographers and is in a state of probation, since it began to appear in the discussions of School Geography mainly from the decade 1990. Therefore, the objective of this work is to discuss theoretical indications for the development of such reasoning in basic education. For this we used the bibliographic research in which allowed us to reach the following results; the structural concepts (space, landscape, territory) and the logical principles (scale, location, delimitation, connection) are the theoretical bases for the development of the geographic reasoning in basic education. Therefore, geographic reasoning is a cognitive process that enables the mobilization of abilities to interpret and act in spatial practices in a critical-reflective way. Its development in the teaching of Geography in basic education requires the scientific foundations of Geography as a science.
\end{abstract}

Keywords: Teaching; Reasoning; Geographical. 


\section{INTRODUÇÃO}

Este trabalho surgiu de reflexões enquanto docente em práticas educativas na educação básica desde 2008 e em pesquisas acadêmicas no campo da Geografia Escolar a partir de 2016. Dessa forma, constata-se na rotina de aula os questionamentos dos alunos do porquê estudar Geografia, dentre os fatores, devido às heranças das práticas pedagógicas mnemônicas pautadas em decorar nomes de rios, cidades, países, capitais de estados. Por outro lado, existem os documentos oficiais como a Base Nacional Comum Curricular (BNCC) que traz como função da Geografia na educação básica estimular o raciocínio geográfico como um processo cognitivo a ser desenvolvido no aluno capaz de propiciar a mobilização de habilidades específicas peculiar da geografia na escolarização básica. Além disso, as pesquisas acadêmicas em geografia escolar tem indicado o raciocínio geográfico como uma cognição geográfica importante no desenvolvimento dos alunos. Assim, este estudo defende o raciocínio geográfico como um processo cognitivo que possibilita a mobilização de habilidades, como interpretar e atuar de maneira crítico-reflexiva nas práticas espaciais.

As pesquisas na área de ensino de Geografia têm buscado reafirmar a função da Geografia tanto na escola na educação básica quanto como um campo de pesquisa na academia. Dessa forma, tem-se buscado uma fundamentação própria por meio da articulação da Geografia acadêmica com outras áreas do conhecimento científico em prol dessa ratificação epistemológica enquanto componente curricular escolar relevante, bem como um campo de pesquisa científica. Dessa forma, as discussões teóricas, em especial pós-década de 1990, têm levado a alguns direcionamentos, por exemplo, do desenvolvimento do raciocínio geográfico junto aos alunos como função da Geografia escolar na educação básica. Isso, pois, o raciocínio geográfico tem sido apontado como uma habilidade cognitiva a ser desenvolvida na prática educativa do professor no ensino superior e no básico. No caso, entende-se neste estudo ser um processo cognitivo o qual propicia múltiplas habilidades, que podem ser apropriadas pelos estudantes para interpretar e atuar de forma crítico-reflexiva em suas práticas espaciais.

Na educação básica, foco desta discussão, tal raciocínio é indicado como possibilidade para ser desenvolvido nas estratégias pedagógicas do professor de Geografia visando à instrumentalização dos alunos para interpretar e atuar nas suas práticas espaciais. Assim, a 
mobilização do raciocínio geográfico é importante porque as relações da sociedade ocorrem no espaço, assim, não existe sociedade a-espacial. Logo, as ações dos sujeitos ocorrem em práticas espaciais as quais são constituídas de um conjunto de ações localizadas espacialmente sobre um substrato natural que constitui a organização geográfica do espaço.

A organização geográfica do espaço é construída nas práticas espaciais as quais podem ser fruto tanto da consciência cognitiva da diferenciação das áreas como de projetos realizados por atores diversos em determinadas sociedades. Assim, o raciocínio geográfico pode ser apropriado como um instrumento psicológico pelos alunos para interpretar como funcionam tais organizações espaciais, bem como também promover atuações em prol de justiça socioespacial. Dito isso, cabe ao professor de Geografia na educação básica organizar situações pedagógicas ancoradas nas dimensões dos conceitos fundantes da Geografia, no pedagógico e na interação com o contexto dos alunos como elementos indicadores para desenvolver o raciocínio geográfico no aluno.

Assim, como o mundo contemporâneo tem sido influenciado por diversos fatores, dentre esses está o processo de globalização econômica, que torna as práticas espaciais cada vez mais complexas. Assim, o raciocínio geográfico é um processo cognitivo que pode ser apropriado pelo aluno para interpretar essas complexidades dos fenômenos espaciais. Dito isso, diante desse contexto mundo e da importância do raciocínio geográfico como uma cognição particular a Geografia, leva-se a questionar: quais são os fundamentos teóricos que podem contribuir para o desenvolvimento do raciocínio geográfico no aluno na educação básica?

Parte-se da suposição de que os conceitos e os princípios da Geografia - como espaço, território, paisagem, região, lugar, localização, delimitação, conexão, rede, escala - são elementos que fundamentam o raciocínio geográfico. E que essas orientações conceituais de analisar o espaço são as matrizes que diferenciam a cognição geográfica das outras, nos componentes curriculares na escola básica. Isso porque as outras disciplinas escolares também têm essa preocupação com a espacialidade, como, por exemplo, a Matemática, a Física, a Sociologia, a Educação Física, mas não com a dimensão da Geografia, pois, a mesma tem uma perspectiva mais ampla e contemplativa da relação sociedade-natureza nos fenômenos espaciais de maneira crítico-reflexiva.

Logo, o objetivo deste trabalho é discutir indicações teóricas para o desenvolvimento do raciocínio geográfico no aluno na educação básica. E para se alcançar tal propósito, apropriou-se da abordagem qualitativa, pois os estudos na área de educação são dinâmicos e 
complexos. Assim, essa abordagem foi fundamental porque ela permitiu realizar interpretações e construção de significados sobre o objeto de estudo - raciocínio geográfico e foi sustentada em uma pesquisa bibliográfica. Sendo assim, por se tratar de uma discussão teórica, o trabalho está organizado em quatro seções, apresenta-se o ensino de Geografia no contexto de mundo contemporâneo, o desenvolvimento do raciocínio geográfico no aluno, fundamentos teórico-metodológicos no desenvolvimento do raciocínio geográfico e considerações finais.

\section{O contexto de mundo e o papel do ensino de Geografia}

O mundo contemporâneo é complexo e marcado por diversas características, dentre essas, a globalização econômica. O fenômeno da globalização tem tentado tanto homogeneizar as espacialidades quanto eliminar as fronteiras por meio da utilização dos recursos tecnológicos. Dessa forma, a globalização é um processo que tem provocado múltiplas consequências, como a interdependência entre as nações nas relações políticas, econômicas e culturais (CAVALCANTI, 2006).

Essas novas experiências do mundo globalizado têm acarretado no agravamento dos problemas ambientais, da violência, da fragmentação territorial, do desemprego, dentre outros. Além disso, as tecnologias da informação e da comunicação têm permitido a simultaneidade e influenciado nas relações sociais, políticas e culturais. Assim, por meio da necessidade do consumo, são promovidas ações de marketing que tentam influenciar os sujeitos a não questionar tais contradições socioespaciais (CAVALCANTI, 2006).

O processo de globalização atual tem sido caracterizado principalmente pela inserção das tecnologias da informação e da comunicação, as quais têm permitido uma forma de difundir uma intensificação das relações econômicas, políticas, culturais a nível cada vez mais global. Por outro lado, tais relações têm também acentuado as perversidades com o aumento dos conflitos, das desigualdades socioespaciais, das migrações forçadas, da xenofobia, dos preconceitos (raça, cor, opção sexual, gênero) e dos impactos ambientais.

Diante de tal contexto, é notável essa influência tanto nas práticas espaciais quanto na produção das ciências, a exemplo da Geografia, que tem quer realizar uma reflexão sobre o seu papel nessa conjuntura complexa enquanto componente disciplinar no currículo escolar. Sendo assim, o ensino de Geografia é um instrumento cognitivo poderoso para os escolares realizarem esse raciocínio nas práticas espaciais, o qual pode lhes permitir habilidades, como 
de relacionar o acontecer em escala global com os seus desdobramentos no local vivido por esses sujeitos (CAVALCANTI, 2006).

Diante dessa complexidade, a Geografia nesse novo contexto tem sido constituída mais plural, reafirma o espaço como seu objeto de estudo e deixa explícita sua definição, como sendo constituído por um conjunto indissociável de sistemas de objetos e de sistemas de ações (CAVALCANTI, 2006; SANTOS, 2014). Essas demandas diante do mundo contemporâneo passam a ser outras em relação à geração a qual foi formada os professores. Nesse contexto, a escola passa a ser questionada e seus conteúdos curriculares são colocados à prova. Dessa forma, com a Geografia não é diferente, uma vez que ela deve buscar refletir sobre possíveis alternativas e, dentre essas, descobrir como o professor aprende para ensinar (CALLAI, 2010).

No Brasil, a Geografia Escolar tem se constituída como campo de pesquisa nas últimas décadas do século $\mathrm{XX}$, em destaque a partir das emergências dos Parâmetros Nacionais Curriculares (PCN), da BNCC, das reflexões acadêmicas, da ampliação das pesquisas no ensino de Geografia. Tal campo tem reforçado a relevância da Geografia enquanto disciplina escolar para o desenvolvimento do raciocínio geográfico. Justifica-se essa indicação em virtude do panorama de mundo apresentado como globalizado, no qual passa a exigir dos sujeitos ainda mais do processo cognitivo da compreensão dos fenômenos do espaço geográfico de forma crítico-reflexiva (CAVALCANTI, 2013).

Não obstante, as disciplinas que desenvolvem raciocínio que possibilita o entendimento e a atuação no mundo em uma perspectiva crítico-reflexiva passam a ser diluídas nos currículos escolares. Sendo assim, o raciocínio geográfico desenvolvido no ensino de Geografia não tem passado ileso a essa lógica, pois tem se tentado suprimi-lo em prol do atendimento da formação voltada mais para o mercado de trabalho, como se pode ver na lei 13.415 da nova reforma do Ensino Médio publicada em 2017.

\footnotetext{
$\S 3^{\circ} \mathrm{O}$ ensino da língua portuguesa e da matemática será obrigatório nos três anos do ensino médio, assegurada às comunidades indígenas, também, a utilização das respectivas línguas maternas.

“Art. 36 . O currículo do ensino médio será composto pela Base Nacional Comum Curricular e por

itinerários formativos, que deverão ser organizados por meio da oferta de diferentes arranjos

curriculares, conforme a relevância para o contexto local e a possibilidade dos sistemas de ensino, a saber:

I - Linguagens e suas tecnologias;

II - Matemática e suas tecnologias;
} 


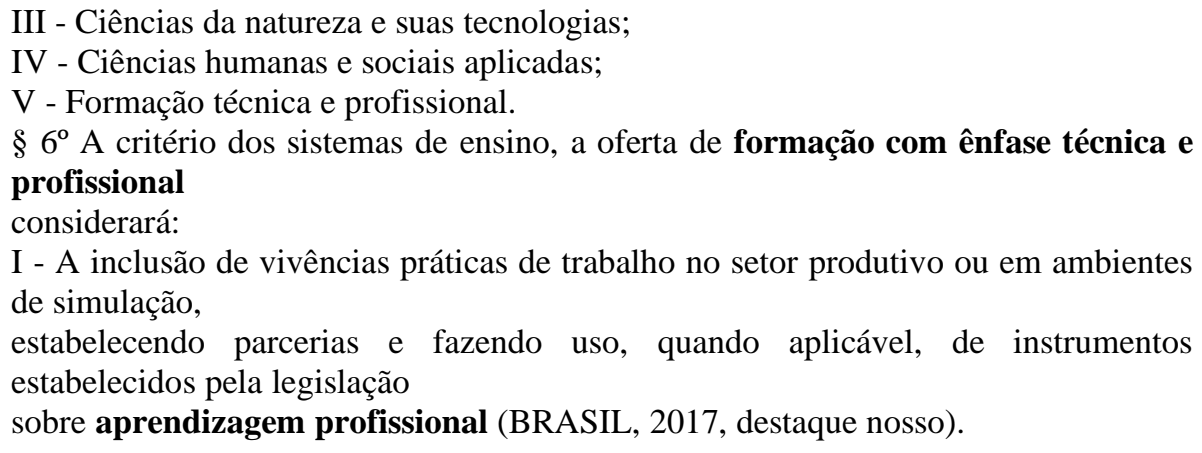

A nova reforma do Ensino Médio foi imposta por uma decisão política arbitrária, e entrou em vigor por meio de um decreto em forma de medida provisória que passou a valer de imediato. De acordo com Saviani (2018), está expresso na LDB (Lei de Diretrizes e Bases) que reformas de ensino neste âmbito, os estados e os municípios devem ser consultados. No entanto, isso não aconteceu e até mesmo os pegou de surpresa por não ter havido tal consulta. Dessa maneira, a reforma se pautou na inserção de conteúdos de disciplinas mais voltadas para atender a demanda do mercado de trabalho em detrimento da formação crítico-reflexiva do aluno, como a do desenvolvimento do raciocínio geográfico realizada no ensino de Geografia.

O raciocínio geográfico é um instrumento cognitivo que pode tanto instrumentalizar o aluno a interpretar de forma crítico-reflexiva tal contexto de mundo, quanto a habilitá-lo a ter uma atuação consciente nas relações sociedade-natureza. Isso porque tal raciocínio é um processo cognitivo capaz de permitir aos sujeitos a diversas habilidades, como as de interpretar e de atuar no mundo por meio da apropriação teórico-metodológico dos conceitos fundantes da Geografia (MORAES, 2018).

Logo, o professor de Geografia tem uma importância fundamental nesse processo, uma vez que ele tem a atribuição de organizar as situações de mediação pedagógica, sejam elas simbólicas ou materiais. E a partir disso, articulá-las por meio de três dimensões basilares defendidas neste trabalho: primeiro, dos fundamentos da Geografia como os conceitos básicos (espaço, território, paisagem, lugar, região) e dos princípios lógicos (localização, rede, conexão, delimitação, escala); segundo, os aspectos didático-pedagógicos (tendência filosófica, psicologia de desenvolvimento, procedimentos didáticos); e, por fim, a interação dos conhecimentos científicos com o contexto do aluno.

\section{O desenvolvimento do raciocínio geográfico no aluno}


A discussão sobre a categoria raciocínio geográfico é recente, mas na Geografia acadêmica foi utilizada pela primeira vez em 1976 pelo geógrafo Yves Lacoste - na obra Geografia serve, em primeiro lugar, para fazer a guerra - e tem aguçado o interesse atual de pesquisadores da Geografia Escolar. Assim, Roque Ascenção e Valadão (2014) ratificam tal afirmativa dizendo que esses estudos ainda são recentes e, portanto, não consensuais entre os geógrafos, não só a expressão raciocínio geográfico, mais outras como pensamento espacial, raciocínio espacial, pensamento geoespacial, para citar algumas.

A contribuição social desta pesquisa decorre de o raciocínio geográfico ser instrumento cognitivo que pode possibilitar aos sujeitos interpretarem e atuarem nas práticas espaciais de maneira crítico-reflexiva. Sendo assim, reforça-se a necessidade de tal desenvolvimento na escola por ser fundamental para que a Geografia cumpra seu papel na educação básica, de desenvolver os estudantes para participarem ativamente na sociedade.

As práticas espaciais são idealizadas por meio de abstrações das operações mentais, como: localizar, selecionar, distribuir, ordenar, posicionar, dentre outras. Elas são construídas na mente por meio da relação cognitiva com a realidade. Assim, essas, por sua vez, são decodificadas pela mente humana nas operações cerebrais em intermédio com apropriação dos conceitos (MOREIRA, 2015). Elas são decorrentes das ações sociais fruto tanto da consciência intuitiva empírica dos homens na diferenciação das áreas, como as de cunho intencional, que são planejadas para atuar nas dinâmicas espaciais (CORRÊEA, 2012).

Nesse sentido, o raciocínio geográfico é um processo cognitivo que pode oportunizar habilidades aos discentes de compreenderem as dinâmicas das práticas espaciais por meio da utilização dos conceitos e princípios geográficos. Esses são os elementos fundantes para o desenvolvimento e a mobilização dessa cognição, como: espaço, território, paisagem, lugar, região e os seus princípios lógicos como: localização, distribuição, distância, extensão, posição, escala, rede, arranjo, configuração.

Dito isso, raciocínio geográfico é uma cognição desenvolvida no ensino de Geografia orientado nos fundamentos da Geografia (SILVA; ROQUE ASCENÇÃO; VALADÃO, 2018). De acordo com os autores, tem crescido a utilização dessa categoria como sendo peculiar ao ensino desenvolvido nas aulas de Geografia, na qual serve de instrumento cognitivo para que os escolares possam interpretar e atuar nas práticas espaciais de maneira crítico-reflexiva.

Moraes (2018) reforça tal perspectiva por meio da indicação dessa possibilidade de interpretação das espacialidades nas cidades por meio da articulação dos princípios lógicos da 
Geografia com a cartografia. Feito isso, os jovens escolares citadinos terão ferramentas para buscar transformar as espacialidades em que vivenciam. Na visão de Filizola (2009), o raciocínio geográfico é uma habilidade específica da Geografia, pois outras ciências também estudam o espaço, mas com modus operandi diferente ao geográfico. Assim, esse raciocínio é uma maneira "poderosa" particular de olhar o mundo e compreendê-lo.

Para Young (2007), a escola tem duas funções, uma de promover "os conhecimentos dos poderosos" que têm como propósito a manutenção do status quo e a outra é de desenvolver nos alunos "o conhecimento poderoso" que se fundamenta nas teorias que os ajudam no processo de formação emancipada. Em concordância dialógica entre Filizola (2009) e Young (2007), o raciocínio geográfico é um instrumento cognitivo "poderoso" que pode potencializar os estudantes a estabelecerem relações crítico-reflexivas em diferentes dimensões das práticas espaciais as quais são concretizadas no espaço geográfico. Neste sentido, esse raciocínio não é o único recurso cognitivo, mas, sem dúvida, pode ser um instrumento psicológico poderoso para a participação ativa dos escolares nos fenômenos espaciais.

Dado o exposto, com os impactos gerados pela globalização, que tem tornado o mundo cada vez mais complexo, por isso, o raciocínio geográfico é uma ferramenta cognitiva que possibilita o entendimento desse processo. No entanto, para que isso ocorra, não basta somente realizar uma leitura das relações locais como eram antes, mas, sobretudo, há a exigência de que os escolares possam fazer análises que interconectam dialeticamente o localglobal (FILIZOLA, 2009).

Ademais, é necessário desenvolver esse raciocínio porque tanto é útil para se fazer estudos de fenômenos espaciais quanto para compreendê-los na dinâmica relacional nas práticas espaciais. Dessa forma, o raciocínio geográfico pode ser desenvolvido no aluno na educação básica para favorecer a interpretação e atuação crítico-reflexiva das espacialidades dos fenômenos geográficos (SILVA; ROQUE ASCENÇÃO; VALADÃO, 2018).

\section{Fundamentos teóricos no desenvolvimento do raciocínio Geográfico}

As práticas espaciais constroem a sociedade geograficamente. Elas se baseiam na localização e na distribuição das ações que resultam na geograficidade. É por meio do espaço que a sociedade se organiza geograficamente (MOREIRA, 2015). Assim, como os fenômenos 
terrestres têm caráter temporal, no entanto, para se realizarem precisam de uma base espacial. Dito isso, e em concordância com Santos (2014), não existe sociedade a-espacial, pois os fenômenos sociais acontecem em recortes específicos na dialética da totalidade em eventos espaço-temporais. Tais práticas espaciais são um conjunto de ações que se localizam espacialmente e promovem impactos no espaço geográfico. Dessa forma, elas alteram ou preservam tanto as formas quanto as interações dos fenômenos espaciais (CORRÊA, 2012).

As práticas surgem tanto da consciência dos homens da diferenciação de áreas espaciais quanto de projetos que cada tipo de sociedade planeja e exerce. Essas podem ser exercidas pelos sujeitos em ações no espaço por meio da seletividade, da fragmentação, da antecipação, da marginalização, da reprodução da região produtora (CORRÊA, 2012). Nesse sentido, a organização geográfica da sociedade é resultado por um lado da consciência do homem sobre a diferenciação espacial que gerará ações de acordo com o local e o tempo na qual está realizando; e, por outro lado, dos projetos que são produzidos para garantir a existência e a reprodução de atividades tanto a nível social quanto produtiva.

Na Geografia Escolar, realizada pelo professor de Geografia na educação básica, se faz necessário que o docente tenha domínio teórico dos conceitos que fundamentam a Geografia enquanto ciência e de compreender como se dá a construção do conhecimento científico no aluno (PIRES; ALVES, 2013). Shulman (2014), denomina tais domínios de conhecimento pedagógico do conteúdo, que tem por base uma amálgama, por meio da apropriação dos conhecimentos didático-pedagógico, do contexto do aluno e do componente disciplinar no qual o professor desenvolve na escola, neste caso, o da Geografia.

O domínio de conhecimento que se requer para a atuação do professor de Geografia na escola básica não é o mesmo da Geografia acadêmica, isso, pois a acadêmica visa à produção do conhecimento científico da Geografia enquanto ciência. A Geografia Escolar é a que é realizada pelo professor de Geografia na mediação pedagógica com seus alunos nas escolas básicas. Sendo assim, o trabalho do professor na educação básica se ancora na Geografia acadêmica e nos conhecimentos didático-pedagógicos, do contexto do aluno, do currículo escolar (prescrito ou oculto), das psicologias do desenvolvimento, dentre outros. Dessa forma, a função da Geografia na escola é desenvolver o cognitivo do aluno para prepará-lo para a atuação nas suas práticas espaciais.

Nesse sentido, a não mobilização do conhecimento pedagógico do conteúdo pelo professor de Geografia na escola básica compromete o desenvolvimento do raciocínio geográfico no aluno e, consequentemente, na sua possibilidade de interpretar e atuar nas 
práticas espaciais de maneira crítico-reflexiva. Sendo assim, na educação básica o professor de Geografia pode articular os conhecimentos da dimensão do desenvolvimento dos sujeitos pela aprendizagem com os fundamentos teóricos da Geografia acadêmica em prol de desenvolver o aluno para atuar nas práticas espaciais.

$\mathrm{Na}$ dimensão pedagógica, a perspectiva da psicologia histórico-cultural, em especial a de Vygotsky, indica-se como uma possibilidade para o ensino de Geografia, pois a formação de conceitos são processos cognitivos responsáveis pelo desenvolvimento do sujeito por meio das funções psicológicas superiores. No ensino de Geografia isso se dar articulado aos conceitos da Geografia, aos conhecimentos espontâneos e aos conhecimentos pedagógicos que culminam no desenvolvimento do raciocínio geográfico. Por conseguinte, a formação dos conceitos se dar por meio da capacidade do sujeito em analisar e sintetizar os processos de interação entre sujeito-sujeito e sujeito-objeto em um determinado contexto histórico-cultural (VYGOTSKY, 2009).

Na perspectiva de Vygotsky (2009), formar o sujeito a pensar por conceitos é um processo dialético e não linear, daí vem o fundamento que se defende neste trabalho do raciocínio geográfico ser processo cognitivo por ser operacionalizado na mente humana formada pela apropriação e interação histórico-cultural. Cabe esclarecer que Vygotsky não se refere à categoria raciocínio geográfico, mas é uma apropriação conceitual que se tem feito desde 2017 para a construção desta categoria por meio de pesquisa bibliográfica e de campo em escolas públicas no Distrito Federal.

Para reforçar a potencialidade do raciocinar por conceitos voltamos à perspectiva vigotskiana. Dessa forma, de acordo Vygotsky (2009), há três estágios no processo de desenvolvimento do pensamento conceitual nos quais apresenta-se a seguir de forma simplória, a saber: sincrético, complexo e o conceitual propriamente dito. Na primeira etapa, o pensamento da criança baseia-se na agregação desorganizada dos objetos e na resolução de problemas, que se dá pela tentativa-erro. No segundo estágio, pensamento complexo, a criança começa a fazer generalização com vínculos concretos com os objetos. Enfim, no terceiro estágio, ao pensar por conceitos, os objetos passam a ser relacionados com os atributos comuns (VYGOTSKY, 2009).

$\mathrm{Na}$ dimensão dos fundamentos necessários para caracterizar o raciocínio geográfico, entende-se tanto pelos conceitos chaves quanto pelos princípios lógicos. Para Corrêa (2012), os conceitos chaves da Geografia são: espaço, território, lugar, região, paisagem. Na visão de Moreira (2015), emergidos entre esses conceitos existe o entrelaçando de tais conceitos com Luz Neto, 2019 ISSN 2594-9616 
os princípios lógicos nos quais os clássicos da Geografia alicerçaram suas análises geográficas, como rede, delimitação, localização, conexão, escala extensão dentre outros. Cabe ressaltar que a classificação dos conceitos fundantes e dos princípios lógicos na Geografia se diferenciam em escolha metodológica dos autores, uma vez que existem multiplicidades de saberes geográficos, desde os primeiros pensadores do espaço, que a nosso ver merecem ainda muitos estudos, como, por exemplo, Heródoto e Estrabão, na Grécia, no período da Antiguidade Clássica.

Dessa forma, por exemplo, Moraes (2005) cita sete princípios lógicos que para os clássicos da Geografia dão unidade à Geografia, que são: individualidade, atividade, conexão, comparação, extensão, localização, delimitação. Para o autor, os princípios lógicos são responsáveis pela unidade e continuidade da Geografia tanto na Geografia tradicional como nos demais momentos de crises das ciências, uma vez que faz parte da história da ciência vivenciar tais dilemas, bem como tem ocorrido na Geografia.

Logo, os conceitos da Geografia que fazem parte de seu arcabouço teórico são diversos, por isso optou-se por discutir os enumerados por Moreira (2015). Para o autor, o que caracteriza a Geografia são os conceitos estruturantes (espaço, paisagem, território) e os seus princípios lógicos (escala, localização, delimitação, extensão, arranjo, conexão, distribuição). Além disso, considera-se as dimensões complexas e profundas desses fundamentos enumerados, pois este trabalho não tem a ambição de discuti-los de forma ampla, mas de somente apresentar a necessidade de suas existências também na mediação do professor na escola.

Ademais, esta discussão é focada no âmbito da Geografia Escolar, que tem como função formar os alunos por meio da apropriação desses fundamentos. Dessa forma, a necessidade desses escolares não é realizar pesquisas científicas para produção acadêmica, mas de se apropriarem desses fundamentos nos conteúdos trabalhados pelos professores de Geografia para desenvolver o raciocínio geográfico em prol de ampliar os horizontes de compreensão crítico-reflexiva das práticas espaciais.

Dito isso, a concepção de espaço é complexa porque envolve elementos concretos e abstratos. O conceito de espaço nem sempre foi considerado como um dos conceitos chaves para a Geografia. Houve uma modificação de olhar de acordo com as correntes do pensamento geográfico (CORRÊA, 2012). Na corrente clássica do pensamento geográfico (1870-1950) deu-se preferência pelo uso de paisagem e de região em detrimento do espaço, apesar de Friedrich Ratzel (1844-1904) ter o utilizado como necessário na sua obra 
antropogeografia. Além dele, Hartshorne (1899-1992) utilizou o conceito de espaço em sua obra, mas em perspectiva de receptáculo dos objetos geográficos. Assim, perdurou até 1950 com a emergência da corrente teorética-quantitativa (CORRÊA, 2012).

Em confluência com Corrêa (2012), a corrente de pensamento teorética-quantitativa (1950-1970) vai considerar o espaço como planície isotrópica por onde os fenômenos espaciais são considerados uniformes. Nessa linha, não se relaciona os fenômenos espaciais em uma dinâmica da produção do espaço. É com a corrente do pensamento da Geografia crítica (1970) que o conceito de espaço vai ser ressignificado. Um dos expoentes desse movimento foi Santos (2014), o qual, no livro A natureza do espaço, o define como um conjunto indissociável e híbrido de sistemas de objetos e de sistemas de ações.

Nessa perspectiva, a priori a essência do espaço geográfico só aparece para os alunos da educação básica se forem considerados os fenômenos espaciais, como constituídos indissociavelmente de sistemas de objetos (rios, florestas, relevo, cidades, indústrias) e de ações (trabalhar, estudar, consumir, viajar). Para ilustrar isso, imagine-se que o professor de Geografia está dando aula em turmas de $9^{\circ}$ ano sobre a globalização. Diante de tal assunto, ele deve abordar o espaço considerando que esse processo se realiza em uma estrutura (objetos) que de acordo com sua densidade técnica terá um fluxo (ações) espacial, os quais constituirão a organização geográfica. Esses sistemas não podem ser desenvolvidos no ensino de forma isolada em virtude que a constituição dos arranjos nesse conjunto de forma peculiar e híbrida. E para que o aluno possa fazer tal leitura é necessário um tipo de raciocínio, que no ensino de Geografia é o geográfico (FILIZOLA, 2009).

Dado o exposto, a importância de se trabalhar o espaço na escola é porque os alunos se organizam, orientam-se e localizam-se no espaço. Além disso, eles interagem com os objetos no espaço geográfico construídos historicamente em substratos físico-naturais. Dito isso, o espaço além de ser um conceito chave da Geografia, também se constitui no seu objeto de estudo enquanto ciência humana, bem como o lócus onde ocorrem os fenômenos socioespaciais.

Por outro lado, paisagem é um dos conceitos que foi muito utilizado até a década de 1960, mas que com o processo de renovação vem sendo esquecido e apropriado por outras áreas do conhecimento como, por exemplo, a Antropologia. Além de ser um grande potencial nas condições de mundo atual marcadas pela linguagem imagética, a qual pode ser explorada pelo conceito de paisagem. Dessa forma, esse conceito mostra um grande potencial para o raciocínio geográfico do aluno, pois a interpretação de paisagem na ótica da Geografia precisa 
mobilizar um conjunto de princípios geográficos para entendê-la como extensão, delimitação, descrição.

A priori, os alunos, na educação básica, em grande parte têm a paisagem como uma “estampa" que não muda e está sempre ali estática. No entanto, esse olhar deve ser mudado de modo que entendam a existência de processos os quais a transforma (CAVALCANTI, 2013). Além disso, de acordo com a autora, o professor pode organizar situações pedagógicas para mostrar e diferenciar a existência de paisagem natural oriunda da dinâmica física da terra no decorrer do tempo geológico. E da paisagem cultural fruto das transformações históricas pelo homem em prol do atendimento de suas necessidades sociais.

O Google Earth, por exemplo, pode ser um recurso digital a ser utilizado para se trabalhar tal conceito por meio de estratégia pedagógica ativa, colocando os alunos para navegar neste aplicativo. Isso lhes dará meios de apropriação da noção da dinamicidade das paisagens e dos processos que a produzem por meio da mobilização do raciocínio geográfico.

Território é outro conceito utilizado pela Geografia, entendido como um conjunto de ações conduzidas por atores que se apropriam do espaço pelo exercício intencional mediado por relações de poder na viabilização de seus projetos de atuação espacial. Para isso, o espaço precede tal exercício, uma vez que ele é base tanto material como imaterial para a realização das intencionalidades dos atores sejam eles hegemônicos ou não hegemônicos (RAFFESTIN, 1993).

Por meio disso, o professor pode organizar situações no Ensino de Geografia para utilizar o conceito de território problematizando-o por meio de várias estratégias pedagógicas como, por exemplo, da utilização da própria sala de aula como recurso. Dessa forma, pode-se utilizá-la didaticamente para levar os discentes entenderem que a própria cadeira em que eles se sentam para assistir as aulas dos professores é um local espacial apropriado pelos mesmos em prol de uma ação intencional, que é estudar. Assim, por exemplo, caso um aluno B venha querer ocupar o espaço antes ocupado pelo aluno A, haverá um conflito no qual o primeiro pode realizar um exercício de poder para garantir um direito de apropriação espacial. Por conseguinte, esse não permitirá que o segundo sente-se porque já está ocupada para atender ao seu interesse em construir o conhecimento escolar ou de qualquer outra natureza subjetiva.

Dado o explicitado, o espaço, a paisagem e o território são os conceitos de base nos quais se estruturam articuladamente com o acesso aos princípios lógicos. Assim, qualquer que seja a intenção de análise dos sistemas de objetos ou dos sistemas de ações se faz necessário localizar, delimitar, conectar, distribuir. Contudo, ressalta-se que tais conceitos e princípios 
devem ser articulados para manter uma relação de interdependência. Sendo assim, eles não devem ser ensinados isolados, mas mobilizados de acordo com a necessidade dos conteúdos geográficos nos quais estão sendo trabalhados em sala de aula. E tampouco rotulá-los de acordo com o tipo de conteúdo a ser trabalhado, por exemplo, conflitos internacionais podem se recorrer não somente a território, mas também a outros como espaço, paisagem, lugar; e nos princípios de localização, rede, escala, extensão.

Dito isso, Pires e Alves (2013) ratificam a assertiva mencionada, pois:

[...] do ponto de vista do ensino de Geografia, esses conceitos se desdobram em diversos temas/conteúdos a serem trabalhados na escola e constituem-se como orientação para a construção de um raciocínio geográfico que organiza, e explica as práticas espaciais cotidianas dos alunos no espaço e no tempo (PIRES; ALVES, 2013, p. 236).

Contudo, esses conceitos podem ser utilizados como instrumentos teóricos para o desenvolvimento do raciocínio geográfico quando se trabalhar os conteúdos do currículo da Geografia Escolar. E não ser memorizados isoladamente como assuntos da Geografia a ser decorados pelos alunos de forma fragmentada como, por exemplo, ensinar o conceito de paisagem sem um eixo de contextualização de conteúdo, de perspectiva pedagógica e de interação com o contexto do aluno. Tais eixos são elos fundamentais no processo de ensinoaprendizagem na mediação do professor de Geografia nos quais podem permitir o desenvolvimento do raciocínio geográfico junto ao aluno.

O desenvolvimento do raciocínio geográfico é um instrumento cognitivo que pode ser utilizado pelo aluno como um recurso psicológico para compreender e atuar de forma críticoreflexiva nas práticas espaciais. Dessa forma, a reflexão sobre o pensamento conceitual vigostkiano e o raciocinar por conceitos da Geografia leva-se a afirmar que o aluno por meio do raciocínio geográfico faz abstrações e generalizações mais amplas com a aquisição deste processo cognitivo no ensino de Geografia. Sendo assim, o aluno a priori faz abstrações por meio da análise e a posteriori realiza generalizações quando está apropriado de ferramentas teóricas que lhes dão a possibilidade de fazer a síntese dos diferentes fenômenos espaciais.

Logo, a Geografia Escolar deve ser desenvolvida nas dimensões, tanto dos seus conceitos como do didático-pedagógica. Sendo assim, o professor de Geografia precisa além de se apropriar dos fundamentos geográficos, também realiza sua atividade em uma perspectiva de desenvolvimento humano, dentre essas, a psicologia histórico-cultural é uma possibilidade. Dito isso, acredita-se que a psicologia histórico-cultural contribui para o 
desenvolvimento do raciocínio geográfico no aluno, principalmente nos conceitos de Vygotsky (PIRES; ALVES, 2013).

Nesse sentido, a contribuição do diálogo com a perspectiva vigotskiana se deve porque o desenvolvimento do raciocínio geográfico é uma abstração cognitiva e por isso, abstrata. Para o processo de raciocínio cognitivo abstrato se faz necessária à aquisição de conceitos mais elaborados, dentre esses, os da escolarização na educação básica. Diante desse diálogo, o aluno traz de seu cotidiano os conceitos espontâneos de suas relações com as práticas espaciais. E cabe ao professor organizar situações propositais em prol de desenvolvê-lo a raciocinar por conceitos abstratos, dentre esses, no ensino de Geografia, o geográfico.

Por fim, a função da Geografia Escolar não é formar um minigeógrafo, não é reproduzir a Geografia acadêmica, mas, possibilitar o desenvolvimento dos alunos por meio da habilidade cognitiva do raciocínio geográfico para interpretar e atuar em suas práticas espaciais de forma crítico-reflexiva (FILIZOLA, 2009).

\section{CONSIDERAÇÕES FINAIS}

O processo de globalização nas condições atuais tem implicado em diversos impactos nas práticas espaciais, sejam elas políticas, econômicas, culturais, ambientais. Dessa forma, reforça-se ainda mais a necessidade do ensino de Geografia em prol da interpretação desses fenômenos espaciais por meio do raciocínio geográfico.

O raciocínio geográfico tem sido uma orientação tanto nos documentos oficiais, como na BNCC, e nas pesquisas na área da Geografia Escolar como uma categoria potencial para o desenvolvimento dos escolares no ensino de Geografia. Na primeira, a BNCC traz essa categoria como habilidades. E na segunda, por meio do levantamento bibliográfico da Geografia Escolar aliada à psicologia histórico-cultural, entende-se por raciocínio geográfico um processo cognitivo potencial na escolarização básica na aquisição de habilidades para interpretar e atuar nas práticas espaciais de forma crítica e reflexiva. Contudo, para isso, fazse necessário que no ensino de Geografia o professor ao trabalhar os conteúdos geográficos utilize nas suas estratégias pedagógicas os conceitos e princípios da Geografia sem esquecer também os conhecimentos espontâneos da realidade dos educandos.

O raciocínio geográfico enquanto uma cognição desenvolvida no ensino de Geografia só é possível quando se apropria de conceitos ou princípios da Geografia acadêmica, a saber: 
conceitos-chaves - espaço, território, paisagem, região, lugar e princípios lógicos como localização, delimitação, extensão, conexão, escala, rede, arranjo, posição, dentre outros. Esses fundamentos, por sua vez, não devem ser ensinados, mas serem usados como ferramentas teóricas para se trabalhar os conteúdos nas aulas de Geografia. Ademais, tampouco devem ser trabalhados de forma desarticulados ou fragmentados aos conteúdos e a realidade dos estudantes na educação básica.

No âmbito didático-pedagógico, a psicologia histórico-cultural, em especial de Vygotsky, apresenta-se como um dos instrumentos conceituais relevantes no desenvolvimento do raciocínio geográfico. Isso devido ao diálogo dessa categoria com a das funções psicológicas superiores, que diz respeito ao desenvolvimento da cognição por meio da apropriação conceitual. Essa cognição geográfica possibilita aos sujeitos interpretar, analisar, generalizar e sintetizar os fenômenos em atributos e categorias abstratas. Para isso, ela se relaciona com outra categoria do autor, funções psicológicas inferiores, que são oriundas dos conhecimentos empíricos. Assim, a formação de conceito é extremamente importante para o desenvolvimento humano na educação, pois instrumentaliza o discente a fazer abstração e generalização dos objetos e das ações na relação espaço-tempo.

Logo, a psicologia histórico-cultural vigotskiana fundamenta a potencialidade do raciocínio geográfico, uma vez que contribui com o desenvolvimento cognitivo dos alunos para interpretar e atuar em práticas espaciais de forma crítico-reflexiva. Dessa forma, estudante munido desta habilidade amplia o campo de compreensão dos fenômenos no espaço geográfico, sejam eles de ordem físico-naturais ou sociais.

Portanto, o raciocínio geográfico é um processo cognitivo importante para os sujeitos interpretarem e atuarem nas suas práticas espaciais no contexto de mundo globalizado de maneira crítico-reflexiva. E para tanto, se requer do professor a mobilização das suas estratégias pedagógicas nas dimensões das orientações dos conceitos fundantes da Geografia, nos fundamentos pedagógicos e na interação com os conhecimentos espontâneos da realidade dos educandos. Feito isso, os alunos podem usar o raciocínio geográfico como uma ferramenta psicológica por meio da mobilização de habilidades geográficas para a transformação das suas práticas espaciais em uma perspectiva de justiça socioespacial. 


\section{REFERÊNCIAS}

BRASIL. Presidência da República: subsecretaria para assuntos jurídicos. LEI No 13.415, de 16 de Fevereiro de 2017a. Disponível em: http://www.planalto.gov.br/ccivil_03/_ato20152018/2017/lei/113415.htm. Acesso em: 31 de Maio de 2019.

Ministério da Educação. Brasília. Base Nacional Comum Curricular, 2017 b.

BRASIL. Secretaria de Educação Fundamental. Parâmetros Curriculares Nacionais: terceiro e quarto ciclos do ensino fundamental: introdução aos parâmetros curriculares nacionais. Brasília: MEC/SEF, 1998.

CAVALCANTI, Lana de Souza. Geografia, Escola e Construção de conhecimentos. 18.ed. Campinas, SP: Papirus, 2013.

Bases teórico-metodológicas da Geografia: uma referência para a formação e a prática de ensino. In: CAVALCANTI, L. S. (org.). Formação de professores: concepções e práticas em Geografia. Goiânia: Vieira, 2006.

CORRÊA, Roberto Lobato. Espaço: um conceito-chave da Geografia. In: CASTRO, Iná Elias de et al. Geografia: conceitos e temas. 15.ed. Rio de Janeiro: Bertrand Brasil, 2012.

FILIZOLA, Roberto. Didática da Geografia: proposições metodológicas e conteúdos entrelaçados com a avaliação. Curitiba: Base Editorial, 2009.

LACOSTE, Yves. Geografia isso serve, em primeiro para fazer a guerra; tradução Maria Cecilia França.19.ed. Campinas, SP: Papirus, 2012.

MORAES, Antônio Carlos Robert de. Geografia: pequena história crítica. 20. ed. São Paulo: Annablume, 2005.

MORAES, Loçandra Borges de. Raciocínio geográfico, cartografia temática e ensino de cidade. Boletim Paulista de Geografia, v. 99, p. 312-331, 2018.

MOREIRA, Ruy. Pensar e ser em Geografia: ensaios de história, epistemologia e ontologia do espaço geográfico. 2.ed. São Paulo: Editora Contexto, 2015.

PIRES, Lucineide Mendes; ALVES, Adriana Olivia. Revisitando os conceitos geográficos. In. SILVA, Eunice Isaias da; PIRES, Lucineide Mendes (Org.) Desafios da didática de Geografia. Goiânia: Editora Puc Goiás, 2013.

RAFFESTIN, Claude. Por uma Geografia do poder. Tradução de Maria Cecília França. São Paulo: Editora Ática, 1993.

SAVIANI, Dermeval. Política educacional no Brasil após a Ditadura Militar. Revista HISTEDBR On-line, v. 18, n. 2, p. 291-304, 2018. 
SHULMAN, Lee S. Conhecimento e ensino: fundamentos para uma nova reforma. Cadernos Cenpec/Nova Série, v. 4, n.2, 2015.

SILVA, Patrícia Assis; ROQUE ASCENÇÃO, Valéria de Oliveira Roque; VALADÃO, Roberto Célio. Por uma construção do raciocínio geográfico para além do pensamento espacial (Spatial Thinking). In: $5^{\circ}$ Colóquio Internacional da Rede Latino-americana de Investigadores de Didática de Geografia, 2018, Pirenópolis. Anais ... Goiânia: LEPEG, 2018.

SANTOS, Milton. A natureza do espaço; técnica e tempo. Razão e Emoção. 4.ed. São Paulo: Editora da Universidade de São Paulo, 2014.

VIGOTSKY, Lev Semenovich. A construção do pensamento e da Linguagem. Tradução Paulo Bezerra. 2. ed. São Paulo: Editora Martins Fontes, 2009.

YOUNG, Michael. Para que servem as escolas?. Educação \& Sociedade, v. 28, n. 101, 2007. 